\title{
Agricultura celular para la producción de pescados y mariscos a base de células ${ }^{1}$
}

\author{
Razieh Farzad ${ }^{2}$
}

Este artículo pretende proporcionar información básica sobre el sistema de producción de pescados y mariscos a base de células a los consumidores y productores de pescados y mariscos.

\section{Introducción}

Los pescados y mariscos, lo que incluye a los crustáceos y a los moluscos, representan el $17 \%$ de la demanda mundial de proteínas animales (Costello et al. 2020). Se proyecta que la demanda de pescados aumente a 140 toneladas métricas en 2050 debido al aumento previsto de la población humana y de los ingresos (Costello et al. 2020). Con el estado actual de las producciones de pescados y mariscos provenientes de la acuicultura y pesca de captura salvaje, va a haber una gran diferencia entre la oferta y la demanda de pescados y mariscos en un futuro próximo (Banco Mundial 2014). Además, la pandemia de COVID-19 mostró las amenazas a la seguridad del sistema alimentario de Estados Unidos y del mundo, así como la importancia de contar con sistemas de producción de proteínas animales duraderas y resistentes (Éliás et al. 2021; Mardones et al. 2020). Esto demuestra la necesidad urgente de un método totalmente nuevo para la producir pescados y mariscos, con el fin de construir una empresa resistente, productiva y flexible frente a los desafíos actuales y futuros. Si bien la acuicultura y la pesca de captura salvaje siguen apoyando la producción sostenible de pescados y mariscos, la producción de pescados y mariscos a partir de cultivos de células y tejidos de peces, denominada agricultura celular (USDA 2020), es un nuevo método que puede ayudar a garantizar la seguridad alimentaria en el contexto del aumento de la población mundial, el cambio climático y la competencia por los recursos naturales.

\section{Método de producción de pescados y mariscos a base de células}

Producir pescados y mariscos a base de células consiste en (1) un tipo de célula apropiado del tejido de interés; (2) medios de cultivo celular para proporcionar nutrientes para el crecimiento de las células; (3) un biorreactor, una embarcación que lleva a cabo reacciones biológicas, para proporcionar el entorno cerrado para sustentar el desarrollo de las células a gran escala; y (4) un armazón de tejido comestible tridimensional diseñado para proporcionar una estructura para el crecimiento y la maduración de la célula con la forma de un producto marino que sea indistinguible de su equivalente convencional (Robio et al. 2019). La primera etapa de la producción de pescados y mariscos a base de células es tomar muestras de células del tejido animal, lo que suele realizarse mediante biopsia sin matar ni dañar al animal. Las células extraídas se utilizarán para preparar bancos de células que puedan utilizarse posteriormente para la producción de alimentos. La siguiente etapa consiste en tomar una pequeña cantidad

1. This publication is FSHN21-2s, one of a series of the Food Science and Human Nutrition Department, UF/IFAS Extension. Original publication date February 2022. Visit the EDIS website at https://edis.ifas.ufl.edu/ for the currently supported version of this publication.

2. Razieh Farzad, profesor adjunto y especialista de UF/IFAS Extension en inocuidad de pescados y mariscos, Departamento de Ciencias de los Alimentos y Nutrición Humana y Florida Sea Grant, UF/IFAS Extension, Gainesville, FL 32611.

The Institute of Food and Agricultural Sciences (IFAS) is an Equal Opportunity Institution authorized to provide research, educational information and other services

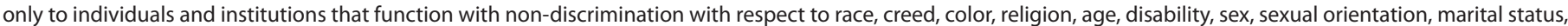

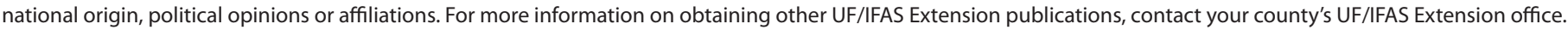
U.S. Department of Agriculture, UF/IFAS Extension Service, University of Florida, IFAS, Florida A \& M University Cooperative Extension Program, and Boards of County Commissioners Cooperating. Andra Johnson, dean for UF/IFAS Extension. 
de células del banco de células y colocarlas en biorreactores, los que favorecen el crecimiento y la multiplicación celular mediante el suministro de nutrientes adecuados y otras sustancias proporcionados por los medios de cultivo celular. Después de que las células se hayan multiplicado varias veces hasta llegar a ser miles de millones o billones de células, se añadirán al biorreactor elementos adicionales como armazones de tejido para proporcionar superficies de fijación de las células, así como para permitir que las células se diferencien en varios tipos de células y asuman las características de las células de músculo, grasa o tejido conectivo. A continuación, el material celular se puede extraer del entorno controlado y preparar con métodos convencionales de procesamiento y envasado de alimentos (FDA 2020b). Aparte de un sistema de producción de proteínas musculares de pez de colores desarrollado en 2002 con financiamiento de la NASA (Benjaminson et al. 2002), no se han publicado ejemplos de productos marinos a base de células. La mayor parte de la investigación y el desarrollo se lleva a cabo en el sector privado, que no está dispuesto a compartir la información con el público.

\section{Desafíos y oportunidades para la industria de pescados y mariscos a base de células}

El método actual para la producción de carne a base de células se basa en la ingeniería de tejidos médicos mediante los avances en las técnicas de bioingeniería y biología celular (Ben-Arye et al. 2019) que se han llevado a cabo principalmente en sistemas de mamíferos. Los tejidos de peces in vitro aún no se han investigado lo suficiente (Robio et al. 2019). La falta de una fuente de células adecuada y de un medio de cultivo celular que tenga todos los nutrientes e ingredientes necesarios (es decir, factores de crecimiento) para el crecimiento de las células son los principales obstáculos para la producción de pescados y mariscos a base de células (Zhang et al. 2020). Los músculos contienen una mezcla de tipos de células con diferentes capacidades diferenciales y de proliferación. Por lo tanto, identificar qué células utilizar para el cultivo, las proporciones de los tipos celulares para el co-cultivo y la reprogramación de las células para que puedan proliferar y diferenciarse en los tipos celulares deseados son los principales obstáculos técnicos (Reiss et al. 2021). El cultivo celular ha dependido tradicionalmente del suero fetal bovino (SFB), componente costoso, insostenible e inconstante en los medios. La producción de medios baratos y sin suero sigue siendo una de las limitaciones más importantes para este campo (Specht 2020). Además, el uso de aditivos, como los antibióticos, en el cultivo de células podría causar problemas relacionados con las normas y la salud humana. La producción a escala de pescados y mariscos cultivados sin necesidad de antibióticos podría ser difícil y requiere una mano de obra muy especializada.

Además, las cifras de producción con las herramientas de bio-manufactura existentes son demasiado lentas, caras e insuficientes para la manufactura a gran escala de cientos de millones de productos cárnicos (Post et al. 2020; Zhang et al. 2020). El proceso de recolección de la carne afecta las características de los músculos de los animales, lo que repercute en las percepciones sensoriales de los productos cárnicos, como la textura y el sabor. Por lo tanto, diseñar construcciones génicas de productos marinos que imiten las percepciones sensoriales más allá de los productos molidos y, al mismo tiempo, proporcionen una mejor nutrición, son obstáculos técnicos y brechas de conocimiento críticos (Post et al. 2020). No hay datos sobre el costo de producción de pescados y mariscos a base de células, pero el precio actual de la carne molida de res a base de células es de 180 a 220 dólares por kilogramo (81 a 100 dólares por libra), en comparación con su equivalente tradicional que tiene un promedio de menos de 9 dólares por kilogramo (4 dólares por libra). Los medios de cultivo suponen entre el $55 \%$ y el $95 \%$ del costo de producción (Specht 2020; Post et al. 2020). Se espera que la construcción de tejidos más complejos cueste entre 5 y 10 veces más que los productos molidos cultivados con células por kilogramo (Specht 2020). Además de los obstáculos técnicos, la integración de las ciencias sociales para comprender la percepción de las partes interesadas es especialmente importante para que el sistema de producción de alimentos tenga éxito y resulte atractivo para los consumidores. Por ejemplo, los filetes de pescado a base de células que se elaboran con suero fetal bovino no serán aceptables por los consumidores veganos. Uno de los principales desafíos para la industria es descifrar la información precisa que puede afectar la aceptación de los consumidores y productores. El cambio de la ética cultural y social hacia el bienestar de los animales cuando existe una alternativa equivalente afectará sin duda a todos los sectores de la ganadería tradicional. Además, el rediseño de la educación y la capacitación desde la escuela secundaria hasta los trabajadores actuales, pasando por los estudiantes de pregrado y posgrado, es esencial para el desarrollo de la mano de obra en una industria de la agricultura celular que actualmente no existe.

A pesar de estos obstáculos, los productos marinos a base de células tienen el potencial más destacado para llegar al mercado a un precio razonable. Las técnicas modernas de acuicultura, como la modificación genética para la 
producción de pescados y mariscos en sistemas acuícolas cerrados (por ejemplo, piscicultura en tierra de especies acuáticas en tanques y estanques), y los estudios centrados en el funcionamiento de los músculos de los peces con consecuencias para la acuicultura, sientan las bases esenciales para la investigación y el desarrollo de la producción de pescados y mariscos a base de células (Robio et al. 2019). Las propiedades de funcionamiento de los cultivos de células y tejidos de los peces, como la tolerancia a la hipoxia (poco oxígeno), la alta capacidad de amortiguación (son menos sensibles a las fluctuaciones de acidez) y las condiciones de crecimiento a baja temperatura hacen que el cultivo celular marino sea una oportunidad atractiva para la producción a escala de pescados y mariscos a base de células (Robio et al. 2019). En mamíferos y aves, la cantidad de células musculares (fibras) se establece al nacer; después, el crecimiento muscular depende del aumento del tamaño de las células (longitud y diámetro) (Rossi et al. 2014). En cambio, el crecimiento muscular de los peces después de salen del cascarón se debe a los efectos combinados de un aumento de la formación de fibras musculares y del aumento del tamaño de las fibras existentes. Por lo tanto, continúa durante toda la vida del pez (Kiessling et al. 2006). Se ha realizado una observación similar en las células musculares de peces que fueron cultivadas en medios de cultivo, lo que demuestra la ventaja de ingeniería de las células de peces sobre la producción de carne a base de células de mamíferos y aves (Potter et al. 2020). Además, los pescados y mariscos se consideran un producto alimentario costoso y de alto valor, y hay algunas especies de peces, como el atún, que no pueden producirse en una instalación de acuicultura en tierra durante todo su ciclo de vida. Esto hace que los pescados y mariscos sean un gran candidato con un alto potencial para las técnicas de agricultura celular que dan lugar a nuevos productos alimentarios en el mercado a un precio competitivo.

\section{Normas y etiquetado de los productos marinos a base de células}

La Administración de Medicamentos y Alimentos (FDA, por sus siglas en inglés) y el Servicio de Inocuidad e Inspección de los Alimentos del Departamento de Agricultura de los Estados Unidos (USDA-FSIS, por sus siglas en inglés) acordaron en 2019 establecer un marco regulador conjunto para la carne a base de células. La FDA supervisaría la recolección de células, los bancos de células y el crecimiento y la diferenciación celular, mientras que el USDA supervisaría la producción y el etiquetado de la carne producida a partir de células de ganado y aves de corral. Sin embargo, la FDA es la única que supervisa los pescados y mariscos a base de células (excepto especies de bagre) y ha solicitado comentarios públicos sobre cómo etiquetarlos (FDA 2020a). Según el acuerdo, la supervisión reguladora de la FDA incluye un proceso de consulta previa a la comercialización y la inspección de los registros y las instalaciones para garantizar que las entidades de cobertura cumplan con requisitos como el registro de las instalaciones y los requisitos de buenas prácticas de manufactura vigentes, análisis de peligros y puntos críticos de control (por ejemplo, normas de inocuidad de pescados y mariscos de la FDA que deben cumplir los productores e importadores de pescados y mariscos), y controles preventivos de la FDA. Las importaciones de alimentos que comprenden o contienen pescado a base de células o células de pescados o mariscos deben cumplir los mismos requisitos legales que los alimentos de producción nacional (FDA 2019).

\section{Conclusión}

La naciente tecnología de la agricultura celular se ha propuesto como una solución para complementar la producción sostenible de pescados y mariscos a través de la acuicultura y la pesca de captura y para suministrar suficientes pescados y mariscos para la creciente demanda en el futuro. Sin embargo, todavía hay muchos obstáculos técnicos y sociales que la industria de la agricultura celular debe superar antes de que los productos marinos a base de células entren en el mercado estadounidense.

\section{Referencias}

Ben-Arye, T., y S. Levenberg. 2019. “Tissue Engineering for Clean Meat Production" [Ingeniería tisular para la producción de carne limpia]. Frontiers in Sustainable Food Systems 3:46. https://doi.org/10.3389/fsufs.2019.00046

Benjaminson, M. A., J. A. Gilchriest, y M.Lorenz. 2002. "In Vitro Edible Muscle Protein Production System (MPPS): Stage 1, Fish" [Sistema de producción de proteínas de músculos (MPPS) comestibles in vitro: Etapa 1, Pescados]. Acta Astronautica 51 (12): 879-889. https://doi.org/10.1016/ S0094-5765(02)00033-4

Choi, K.-H., J. W. Yoon, M. Kim, H. J. Lee, J. Jeong, M. Ryu, C. Jo, y C.-K. Lee. 2021. "Muscle Stem Cell Isolation and In Vitro Culture for Meat Production: A Methodological Review" [Aislamiento de células germinales de músculos y cultivo in vitro para la producción de carne: Revisión metodológica]. Comprehensive Reviews in Food Science and Food Safety 20 (1): 429-457. https://doi. org/10.1111/1541-4337.12661 
Costello, C., L. Cao, S. Gelcich, M. Á. Cisneros-Mata, C. M. Free, H. E. Froehlich, C. D. Golden, et al. 2020. “The Future of Food from the Sea” [El futuro de los alimentos del mar]. Nature 588 (7836): 95-100. https:// doi.org/10.1038/ s41586-020-2616-y

Éliás, B. A., y A. Jámbor. 2021. "Food Security and COVID-19: A Systematic Review of the First-Year Experience" [Seguridad alimentaria y COVID-19: Revisión sistemática de la experiencia del primer año]. Sustainability 13 (9): 5294. https://doi.org/10.3390/su13095294

FDA. 2019. "Formal Agreement between FDA and USDA Regarding Oversight of Human Food Produced Using Animal Cell Technology Derived from Cell Lines of USDA-amenable Species" [Acuerdo formal entre la FDA y el USDA con respecto a la supervisión de alimentos para consumo humano producidos con tecnología celular animal derivada de líneas celulares de especies susceptibles del USDA]. Consultado el 9 de julio de 2021. https://www. fda.gov/food/domestic-interagency-agreements-food/ formal-agreement-between-fda-and-usda-regardingoversight-human-food-produced-using-animal-cell

FDA. 2020a. "FDA Seeks Input on Labeling of Food Made with Cultured Seafood Cells" [La FDA solicita comentarios sobre el etiquetado de alimentos elaborados con células cultivadas de pescados y mariscos]. Consultado el 9 de julio de 2021. https://www.fda.gov/food/cfsan-constituent-updates/ fda-seeks-input-labeling-food-made-cultured-seafood-cells

FDA. 2020b. "Food Made with Cultured Animal Cells" [Alimentos elaborados con células cultivadas de animales]. Consultado el 9 de julio de 2021. https:// www.fda.gov/food/food-ingredients-packaging/ food-made-cultured-animal-cells

Kiessling, A., K. Ruohonen, y M. Bjørnevik. 2006. “Muscle Fiber Growth and Quality in Fish" [Cultivo de fibras musculares y calidad en los peces]. Archives of Animal Breeding 49 (Número especial): 137-146. http://hdl. handle. net/11250/297126

Mardones, F. O., K. M. Rich, L. A. Boden, A. I. MorenoSwitt, M. L. Caipo, N. Zimin-Veselkoff, A. M. Alateeqi, y I. Baltenweck. 2020. "The COVID-19 Pandemic and Global Food Security" [La pandemia de COVID-19 y la seguridad alimentaria mundial]. Frontiers in Veterinary Science 7:578508. https://doi.org/10.3389/fvets.2020.578508
Post, M. J., S. Levenberg, D. L. Kaplan, N. Genovese, J. Fu, C. J. Bryant, N. Negowetti, K. Verzijden, y P. Moutsatsou. 2020. "Scientific, Sustainability and Regulatory Challenges of Cultured Meat" [Desafíos científicos, reguladores y de sostenibilidad de la carne cultivada] Nature Food 1 (7): 403-415. https://doi. org/10.1038/s43016-020-0112-z

Potter, G., A. S. T. Smith, N. T. K. Vo, J. Muster, W. Weston, A. Bertero, L. Maves, D. L. Mack, y A. Rostain. 2020. "A More Open Approach Is Needed to Develop Cell-Based Fish Technology: It Starts with Zebrafish" [Se necesita un enfoque más abierto para desarrollar la tecnología de peces a base de células: todo comienza con el pez cebra]. One Earth 3 (1): 54-64. https://doi.org/10.1016/j. oneear.2020.06.005

Reiss, J., S. Robertson, y M. Suzuki. 2021. "Cell Sources for Cultivated Meat: Applications and Considerations throughout the Production Workflow" [Fuentes de células para carne cultivada: Aplicaciones y consideraciones durante el flujo de trabajo de producción]. International Journal of Molecular Sciences 22 (14): 7513. https://doi.org/10.3390/ ijms22147513 